\title{
Why do people prefer pain, suffering and death, over life, wellness and happiness?
}

\section{Opinion}

Recently a friend's husband (Ellen Jaffe Jones) had a major heart attack and almost died. He had major surgery and is now in a long period of recovery. Looking back, he now wishes he had heeded his wife's long standing advice to consider a Plant Based Lifestyle as she has for a number ofyears. Well, NOW he is very focused on healing and has accepted a Plant Based Diet as the best means to stay alive.

Why didn't he do this before? Why, now, almost on his deathbed does he consider the simple approach of diet and lifestyle when it is almost too late?

This is an all too familiar story and one we hear all the time. Cancer patients prefer radiation, chemotherapy and surgery as the best way to treat their disease when simpler solutions are readily available that may, just may, save their lives without the horrendous and torturous treatments prescribed by the majority of doctors. Very few are actually cured and many suffer and die more from the treatment than the actual disease!

As a Natural Holistic Survivor of prostate cancer (diagnosed some 5years ago), I think I can speak out about this and other subjects concerning so many lifestyle diseases that Americans and others suffer. (http://prostatecancerfight.com/)

Yes, it is the Lifestyle that is making most Americans fat, sick and nearly dead. Poor performance in school and at work, declining energy levels and the dramatic rise in cancer, heart disease and diabetes two, is a pandemic impacting people, businesses and the very fabric of the USA.

Corporate executives are dropping dead at an earlier and earlier age; often in the prime of their productive lives. They looked and thought they were healthy but it was all about the outside appearance. Their internal organs were deteriorating while on the outside they looked the picture of health.

Overwhelming scientific evidence confirms that vitamin deficiencies are associated with disease and the overall condition of one's health. Vitamin, mineral, and antioxidant deficiencies have been shown to suppress immune function and contribute to chronic degenerative processes such as arthritis, Alzheimer's, cardiovascular disease, and diabetes two.

\section{Nutritional deficit}

\section{Why are so many people deficient in basic nutritional needs? DIET!}

Humans are supposed to get all of their vital dietary components from the FOOD they consume. But the diet of many/most individuals is almost totally bereft of essential nutrients. Fast, and overly processed, food filled with saturated fat, junk food, soda and soft drinks filled with sugar make up a major part of the daily diet of too many individuals.

\author{
Volume 3 Issue 2 - 2015
}

\author{
Skip Stein \\ Plant Based Lifestyle Consultant, Whole Foods 4 Healthy Living, \\ USA
}

Correspondence: Skip Stein, Plant Based Lifestyle Consultant, Chief Operating Officer,Whole Foods 4 Healthy Living, Orlando, Florida, Tel 4076836816,

Email skipstein@wholefoods4healthyliving.com

Received: December 05, 2015 | Published: December II, 2015

Most people just do NOT understand what a 'healthy diet' consists of. There are thousands of dietary books recommending this and that and almost all of them are wrong, misleading or flat out deceptive. Few have any supporting scientific evidence to back their recommendations but are mostly filled with conjecture, specious arguments and worse, lies. Most have an agenda to promote either a product or the diet/book itself and has little to do with actual benefit to the Life and Wellness of the reader/consumer.

Too many dietary approaches consist of fad based 'feel good' approaches. Whether it's the cave man diet, vegetarian or vegan, a diet is not a Lifestyle. Diets are usually terminal (in more ways than one) ways to eat and have an end date when the diet will end. Even when good results are obtained with weight loss, lowered cholesterol and such, at the end of the diet period the weight comes back and the cholesterol rises once again.

These on again and off again diets are worse than just avoiding the pain, pressure and suffering that many/most diets inflict. People who want to regain or maintain their health must consider their Lifestyle, not their diet. Lifestyle is more that what you eat, it is how you LIVE.

Living a vibrant, long and healthy life is the goal/aspiration for most people. Few want to spend their latter years in a hospital bed, hooked up to machines, on drugs and undergoing surgery just to extend their miserable lives a few more days/hours. That is not a lifestyle but a death spiral that No One should need to undergo.

When there ARE alternatives, ones proven by countless thousands over years and years, why do so many ignore/refuse/reject these simple options. Changing one's lifestyle and diet is a whole lot easier, cheaper and more pleasant than suffering the side effects of current therapies and drugs (have you actually listened to those TV commercials listing the side effects of almost every commercial drug advertised?) 


\section{Easy is better}

WHY? Why do so many seem to ignore the Easiest Solution? Maybe because it is easy and folks have been brainwashed that pain and suffering is necessary? The phrase 'no pain, no gain' has been around for a long time and there is nothing further from the Truth than this. Sure exercise to build muscle mass (especially for couch potatoes) can cause some discomfort but not near the pain and suffering that most surgeries, chemo therapies, and other treatments inflict. Most people are not triathletes competing in ultra-fit competitions.

People have been brainwashed by TV commercials, drug company advertisements that there is (or will be) a pill for all your ills. The 'Quick Fix' is the easiest solution but no one ever considers the downside and side effects of the Magic Pill solution. Chemical therapies are toxic and you just cannot Poison a Sick Person Well!

It is So much easier to just eat your way to Health \& Wellness the Plant Based Way. Sure, it takes TIME for your body to adjust and detoxify itself from all the lousy stuff you have been consuming. It does take TIME to learn a new way of living, the Plant Based Way. You cannot magically change your body, it takes time to actually regrow itself! The cells in your body die by the millions every day; taste buds are replaced every 10 to 15 days! What you need to do is build new cells with better materials; you ARE what you eat, so make what you eat the most nutritious and delicious stuff possible!

\section{Nothing is that easy}

The next obstacle, one that is often the most difficult, is you must learn to make use of the most underutilized room in most homes; The Kitchen! You must learn that you can't just subsist on processed/ packaged foods. The closer you get to eating Whole Foods the better you will be. Fewer preservatives, less processing makes things taste better and are better for you! This means you have to actually COOK and prepare some/all of your own meals. Just think of all the money you will save by spending a bit of time in your own kitchen. Most nutritious meals can be prepared quickly/easily in 30minutes or less. You can hardly go to a drive-thru or order a pizza faster than that! And is is CHEAPER!

Cooking your own meals for you and your family is a rewarding experience but for most a learned one. If you have never/seldom used the Kitchen you will have to Learn. Learning takes effort to be prepared to spend some time reading and practicing! Think of cooking as not a chore but a fun time to relax, forget about the office/work and be creative. Let yourself experience the wonders of creating delicious and nutritious meals.

Nothing worthwhile is ever easy. Learning and practicing new skills takes effort but the rewards are phenomenal. Not only will you save money, your health will improve and the FOOD will begin to taste marvelous; better than ever before. And it can be FUN!

If you are a single guy, learning how to cook is a marvelous way to attract smart, intelligent and beautiful women! Yea, they love a guy who can cook! Gals, you too. Being able to cook a delicious and healthy meal is, and has been, the way to a man's heart!

Surviving on fast food has dulled/destroyed people's taste buds. Taste buds go through a life cycle where they grow and then die and are sloughed away. Their normal life cycle is anywhere from 10 days to two weeks. This means that in just over 10days you can learn to taste the whole new world of Plant Based Food! It is gradual but the end result will amaze you.

\section{Eat the rainbow}

The foods you thought you didn't like you will find taste better and better. The more colorful the food the better is is for you! So appearance matters just as does the aroma/smell. Staying away from black and brown foods is a great rule of thumb. Meat is read only because of the blood being hit by air born oxygen; not because it has much nutrition! Eating the rainbow is a good rule of thumb. Vegetables are colorful for a reason; to attract YOU to eat them!

To maximize the benefit of eating a Plant Based diet, variety is the key. A balanced diet filled with whole foods, naturally harvested and with few preservatives should be the goal. A few guidelines:
i. You can never eat too many greens!
ii. Beans are Cheap and full of nutrition!
iii. Natural Whole grains are better!
iv. Almost any combination of vegetables tastes great!

The key to a healthy body is overall process health. Variety is the spice of life as many say, so get some spices going in your food. Many spices have amazing health benefits (too many to discuss in this short item). Wondrous ones like cinnamon, turmeric and more are terrific additions to the flavor pallet of just about any food you prepare!

\section{Eliminate the waste}

A Plant Based Diet and Lifestyle will make you move externally and internally! Remember, there was no fiber in all that meat, fish, dairy and eggs you used to consume so you felt bloated, sluggish and tired all the time. NOW, that will not be a problem! Trust me!

You will GO and GO often on a proper Plant Based Diet; all that fiber you are eating will go through and clean you out! So be prepared to allocate a bit of time eliminating waste!

Make sure you drink lots of clean water (no soda or other high sugar drinks) to help your body naturally cleanse and maintain your cell hydration. Fluids (much of it water) is key to a healthy cell and body in general, so DRINK! Always carry a refillable bottle with you full of clean water and sip, sip, sip all day long!

\section{Boost your immune system}

Another fantastic benefit of a Plant Based Lifestyle is that you seldom (if ever) get sick! It's true! Not only will you prevent and even reverse major disease you might have had, you will seldom, if ever get sick. If you do, it will be a milder version of whatever it would have been.

Charlotte Gerson (Gerson Clinic) has a famous and often repeated quote: "When the body heals, it heals everything." If you started this Lifestyle approach due to a specific ailment, like cancer, heart disease or diabetes, you will find that other ailments also reverse or improve. Arthritis, Osteoporosis and even skin complexion and tone will improve.

Because your gut is the home for much of your natural immune system, keeping healthy gut bacteria is a key component and benefit of a Plant Based Lifestyle.

\section{Get Off Your Ass and MOVE!}

You must move! I don't mean run a marathon or anything like that. 
Just get up and move around. Take a walk at lunch, in the evening or better in the morning. Many companies are offering standing workstations and treadmills, you would be surprised how many steps you could walk and not even realize it.

I'm giving myself a standing desk/treadmill for Christmas this year! You can do it in front of the TV while you watch your favorite programs. Some of the smaller/cheaper treadmills don't take up much space and many are collapsible for easy storage.

Invest in some tech to help you! There are numerous new gadgets to help you monitor and encourage your new approach to Health \& Wellness. I've purchased the new Garmin Vivofit wrist bands for us this year. I like them because you don't have to lug your cell phone to make them work and the battery life is One Year! They have a feature to warn you when you've been sitting too long!

\section{Sleep better and longer}

Your new Plant Based Lifestyle will make your brain work better, clearer and more effectively just as it will with your entire body. More energy all around!

The added benefit is that you will get more work done, quicker and better than ever before! This give you time for the longer, healing sleep you might have been missing.
Too many think that working harder/longer is better when working Smarter is the best way to really accomplish anything. I've known people who put in major long hours but get little accomplished while others, work regular hours and go home to their families yet get MORE done! Long hours are smoke and mirrors to impress the boss but in reality accomplish little but degrade ones health (and the good bosses know this!).

Sleep is imperative for your peace of mind and wellness of body. You body heals during sleep. Your mind reorganizes, files and builds synaptic relationships to knowledge learned; all while you sleep (perchance to dream?).

Don't make a habit of hitting that snooze button. Get your butt out of bed and moving. If you need an alarm to wake up, you may not be getting enough sleep. Train your body/mind to wake you up naturally after 8 or even 9 hours of restful sleep. Think this is impossible? You won't after a relatively short time with your new Plant Based Lifestyle.

\section{Acknowledgements}

None.

\section{Conflict of interest}

Author declares that there is no conflict of interest. 